\title{
Unpacking the Relationship Between Science Education and Applied Scientific Literacy
}

\section{Amanda Crowell \& Christian Schunn}

\section{Research in Science Education}

ISSN 0157-244X

Res Sci Educ

DOI 10.1007/s11165-015-9462-1

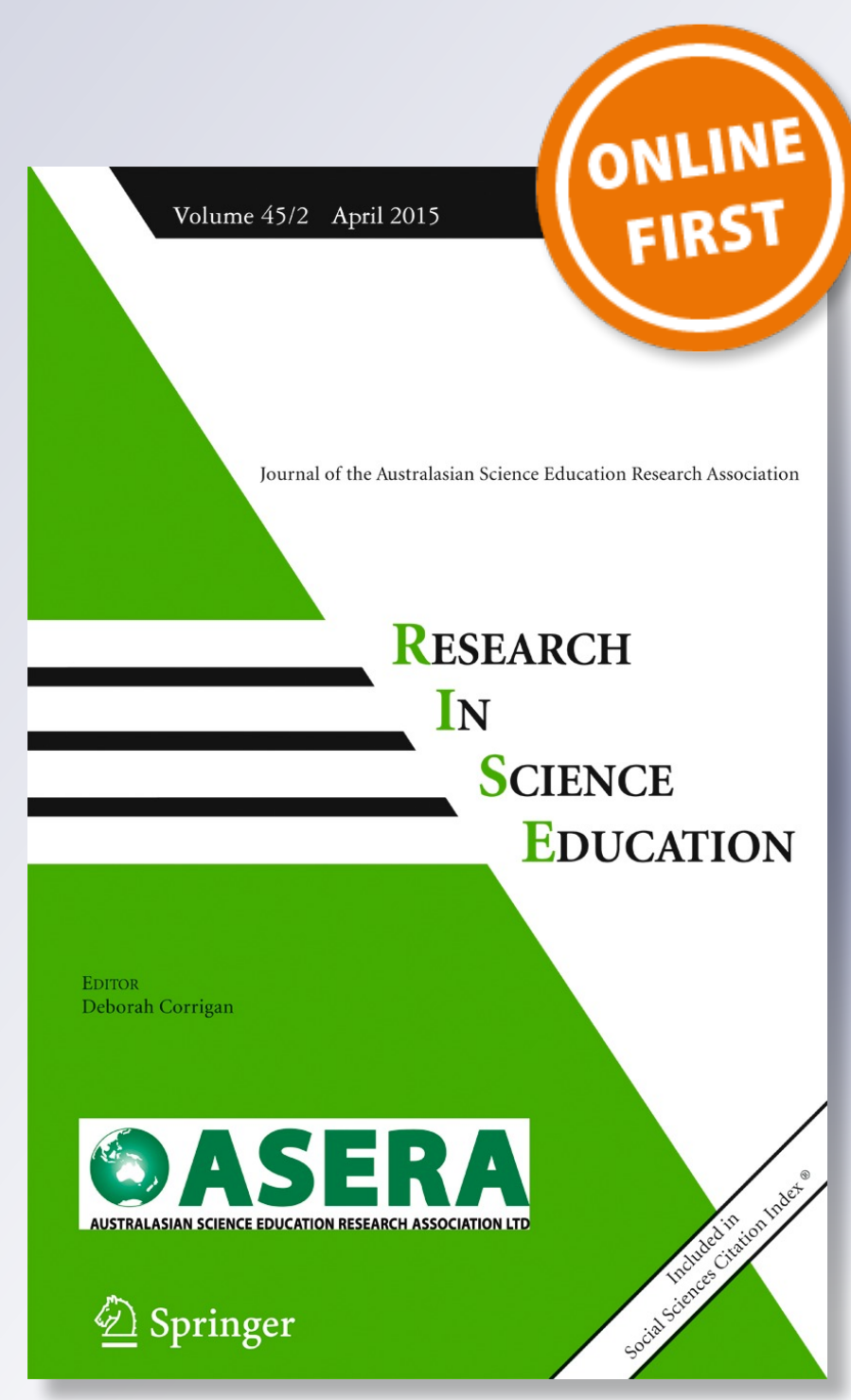

算 Springer 
Your article is protected by copyright and all rights are held exclusively by Springer Science +Business Media Dordrecht. This e-offprint is for personal use only and shall not be selfarchived in electronic repositories. If you wish to self-archive your article, please use the accepted manuscript version for posting on your own website. You may further deposit the accepted manuscript version in any repository, provided it is only made publicly available 12 months after official publication or later and provided acknowledgement is given to the original source of publication and a link is inserted to the published article on Springer's website. The link must be accompanied by the following text: "The final publication is available at link.springer.com". 


\title{
Unpacking the Relationship Between Science Education and Applied Scientific Literacy
}

\author{
Amanda Crowell • Christian Schunn
}

(C) Springer Science+Business Media Dordrecht 2015

\begin{abstract}
Scientific literacy has many meanings: it can be thought of as foundational knowledge, foundational critical thinking skills, or the application of these two foundations to everyday decision making. Here, we examine the far transfer scenario: do increases in science education lead to everyday decision-making becoming more consistent with consensus scientific knowledge? We report on a large sample of employees of a mixed urban/rural county representing a diverse range of careers, who completed an anonymous survey about their environmental conservation actions at home, as well as their general education level and their science coursework. Across broad and narrow measures of science education, we find little impact on action. Possible causes of this failure of transfer and the implications for changes in science instruction are discussed.
\end{abstract}

Keywords Science education · Scientific literacy

\section{Introduction}

Scientific literacy, in its most basic form, can be thought of as a baseline of understanding of science needed for all (see DeBoer 2000; Roberts 2007; Norris and Phillips 2003 for reviews). Different researchers have argued for different needs that are served by science knowledge and, subsequently, different measuring sticks to determine whether an individual is scientifically literate. An older example is the argument that basic science knowledge is necessary to be an "educated" person (see Miller 1983 for review). The premise of this argument is that the science knowledge one attains in science courses taken in high school and university is part of a broad spectrum of general information needed for one to knowledgeably engage both professionally and personally.

Other researchers argue that learning science provides a unique opportunity to develop a different kind of general knowledge: critical thinking skills (e.g., Hurd 2000). In this case, the premise is that science is well situated to provide opportunities to critically inquire, utilize evidence, learn principles of controlled and comparative investigations, and apply problem solving to novel situations. Additionally, the practices of science are an embodiment of an advanced epistemology that conceives knowledge as negotiated and ever changing (Hofer and Pintrich 1997; Sismondo 2004). Exposure to and engagement with science, then, may allow

A. Crowell $(\bowtie) \cdot$ C. Schunn

Learning Research and Development Center, Office 816, Pittsburgh, PA 15260, USA

e-mail: crowell@pitt.edu 
for cognitive skill development and epistemological sophistication, which will help the economy by making the workforce more globally competitive (National Center for Education and the Economy 2007; Thomas and Brown 2011).

Taking a step beyond the notion that scientific understanding confers direct benefits to the individual are those who believe this knowledge and these skills facilitate action. For example, being scientifically literate might incite more individuals to pursue careers in science and technology, two important industries for a country's economic health (Bybee and Fuchs 2006). There are others, however, who assert that the assumed causal pathway between a scientifically literate populace and greater economic health through greater productivity in science, technology, and engineering is not justified at each step and is likely to be more about inequality in science opportunity than raising the level of literacy of the general population (Roschelle, Bakia, Toyama, and Patton 2011).

Moving outside of formal science to the purposes of science for those who will not engage in a career in science, some argue that scientific literacy promotes the ability to critically consume reports of science. Miller (2004), whose measure of scientific literacy is based upon this view, argues that the baseline of science knowledge one obtains through science course taking is that which is required to read and have an opinion about new and evolving scientific discoveries. Such knowledge and resultant voting behavior would be both a safeguard against dangerous scientific advancements and a means of ensuring public support for innovation. Echoing this sentiment is the recent conceptualization of scientific literacy by the Program for International Assessment (PISA), which defines scientific literacy as an understanding of the contexts, competencies, knowledge and attitudes that future citizens would need to "engage in science-related issues, and with the ideas of science, as a constructive, concerned, and reflective citizen" (OECD 2006).

Finally, there are others who argue that scientific literacy improves the likelihood that when one is confronted with dilemmas in which science knowledge plays a big role, one would be more likely to act in concert with scientific consensus (Crowell and Schunn 2014). One might call this the applied aspect of scientific literacy: that is, one's likelihood to apply one's scientific knowledge to one's everyday life (Jenkins 1999; Feinstein 2010, 2012). One example where one might make a decision that would be better informed by science is health (Peerson and Saunders 2009). When one is confronted with an everyday decision regarding one's health, a scientifically literate individual would act in a manner supported by science, assuming science has relevant information for the health issue at hand. If this idea holds, then there should be a relationship between greater scientific literacy and better health. Given that there are health issues that are growing in the general public, this would be a benefit indeed. For example, obesity is an epidemic across the age spectrum but particularly alarming is the steep rise in type two diabetes (previously an adult onset disease caused by obesity) in overweight adolescents (Rabin 2012).

Another such area is environmental conservation - the issue on which we focus here. While there is a debate about the scope of human-influenced climate change, there is scientific consensus that human activities are contributing to unsustainable environmental conditions (Intergovernmental Panel on Climate Change 2007a). Indeed, scientists warn that continuing on current trajectories will likely lead to shortages of clean water and food (Durack, Wijffels, and Matear 2012), higher incidences of catastrophic weather events, and changes to animal and insect ecosystems which could lead to species instability and extinction (Intergovernmental Panel on Climate Change 2007b) The obesity epidemic and environmental conservation are only two examples of instances where applied scientific literacy would be beneficial-i.e., action in concert with scientific consensus would improve or reverse an alarming trend. We opted to focus on environmental conservation because there is substantial scientific consensus, there are a variety of actions everyone can take across contexts, and the problem is of ever-increasing concern.

Each conception of scientific literacy is tied with a common thread: scientific literacy is conferred by way of education. Indeed, scientific literacy is often the reason for requiring all 
students (not just those interested in pursuing a career in science and engineering) to take a baseline of science courses. PISA goes so far as to declare that scientific literacy is the "essential goal of science education" (OECD 2006). It is this relationship between science education and applied scientific literacy that we seek to examine here; particularly, how does education impact the decisions one makes regarding environmental conservation in the home?

In addition to assessing the relationship between course taking (education) and action (applied scientific literacy), we also assess the relationship between one's exposure to science and one's perceptions of oneself as able to attain new knowledge when the need arises. Confidence in one's ability to attain new knowledge is particularly important to this applied element of scientific literacy in part because new scientific knowledge must often be acquired to deal with scientific issues as they present in our everyday life. Therefore, we refine the knowledge element of scientific literacy to be one's perceived knowledge attainment ability (PKAA); that is, in the context of conflicting opinions, how sure is an individual that he or she could come to an understanding of an environmental conservation issue?

Our focus is on one's perceived competence rather than one's actual competence because the literature on perceived competence indicates that the two are not always highly correlated and it is perception that drives one's likelihood to participate in an activity (e.g., Bandura 1986; Carroll and Loumidis 2001). Further, we focus on perceptions about ability to attain knowledge rather than perceptions of existing knowledge because specific actions have many details that are highly unlikely to be presented within high school or college science classes. The connection of coursework to informed decision making in particular applied settings must involve some additional information acquisition. Indeed, many science courses include the ability to decipher new research within the domain as an explicit goal of instruction (Norris and Phillips 2003; Phillips and Norris 1999; Sutman 1996). Finally, we have found that PKAA is an important predictor of action in the same domain being studied here (Crowell and Schunn 2014); here, we examine whether education impacts PKAA.

Perceptions of competence are typically measured via survey. Best practices in the measurement of competency beliefs recommend describing particular situations and asking respondents to estimate their ability to succeed in that situation (Bandura 2001). We use this approach, and our prior work suggests our particular survey questions of PKAA have good psychometric properties (e.g., good reliability/internal coherence).

In sum, we are asking the following questions:

1. Does being more educated (generally, and in science) correlate with a greater likelihood to act in concert with scientific consensus?

2. Does exposure to science content knowledge increase one's perceived knowledge attainment ability (a key predictor of literate action)?

\section{Method}

Participants

Participants were recruited from the employee pool of a mixed urban/suburban county in the American Midwest, including a wide range of occupations such as lawyers, secretaries, administrators, janitors, road repair workers, parks management, and city officials. Of the 6800 county employees, $738(11 \%)$ at least partially completed the survey. Though we do not have information about those who did not complete the survey, separate links were sent to different departments and respondents returned from almost all links, indicating that our participant pool 
represents many different departments. Participants were $67 \%$ female and predominantly (89\%) white. The participants were generally well educated with $64 \%$ holding a bachelors degree or higher, $29 \%$ with an associates degree, and $7 \%$ without a university level degree. Twenty-five percent of the sample held a degree in math, science or engineering (MSE), and most of these (15\% of the sample; $60 \%$ of those with MSE degrees) held degrees in science.

\section{Sampling Procedures}

All county employees were notified of the opportunity to participate in the survey by email and notifications placed in the payroll envelopes. They were offered the opportunity to take the survey online or to take it on paper and fax it to the researchers. Only seven participants opted to take the survey on paper.

Notifications informed county employees that the office of sustainability was collecting information about employee actions regarding environmental conservation. Participants were assured that all responses were anonymous, collected by an independent university organization, and that every entry would qualify for a random drawing; 50 randomly chosen participants were awarded a $\$ 100$ prize. Responses were accepted over 21 days: 126 partial and 612 complete responses were collected. Only the complete surveys (excluding the page where personal information was collected for entry into the drawing) were included in the analyses.

\section{Measures}

Sustainable Action Survey Participants completed the Sustainable Action Survey (Crowell and Schunn 2014), a survey including questions regarding each of the five common actions that can be enacted at home and have significant environmental conservation benefits. These actions were recycling, reducing water usage, reducing energy usage, bundling driving to reduce gas (petrol) usage, and purchasing sustainable products (see Appendix A for verbatim questions). We focus on actions at home because previous work (Crowell and Schunn 2014) indicates that engaging in conservation actions at work or in the public sphere is less common if one is not already engaged in conservation at home. Focusing on actions at home also reduces variability in opportunities to engage in conservation actions across different job categories and responsibility levels.

The first question asked how often the participant engaged in the action at home (ranging from "all the time" to "never") and was followed by a series of statements about that action, each of which were found to significantly (and independently) predict engaging in the such actions (Crowell and Schunn 2014). Specifically, respondents indicate whether they think that the action makes a difference to environmental sustainability, saves money, is convenient, sets a good example, and is responsible; the participants were asked how much they agreed with each statement (answers ranged from "strongly agree" to "strongly disagree").

Perceived Knowledge Attainment Ability (PKAA) The last question of each set assessed perceived knowledge attainment ability:

"Imagine you are at a party where two people are arguing about the importance of recycling. One person says that recycling has NO long-term impact on environmental sustainability, and another person says that recycling does have a long-term impact on environmental sustainability. You decide to do some research to figure out who is right. How sure are you that you have the science knowledge to understand what you read?" 
Answer options ranged from "very sure" to "not sure at all." An aggregate score is computed across the five questions and has high reliability (Cronbach's alpha $=0.96$ ).

Demographics and Course Taking The survey concluded with a series of demographic questions including possible confounds such as gender and questions about how much concern for environmental conservation was expressed in the home in which one was raised. Finally, course taking was assessed via structured self report. Participants were asked to self report their highest degree and were then prompted to select how many courses from each science domain they passed in high school, university, and graduate education. Respondents were only asked about relevant education levels (i.e., one who had a high school diploma was not asked about university course taking).

\section{Results and Discussion}

We begin with the general question of whether being more educated improves one's likelihood to act in concert with scientific consensus. We compared individuals with no college education, some college education (including those with an associates degree) and a bachelors degree or higher. We hypothesized that more education would positively influence one's likelihood to engage in actions that are in concert with scientific consensus.

Analysis of covariance (ANCOVA) showed a main effect of education level, $F(2,602)=$ $4.01, p<.05$, partial eta squared $=0.01$. There was no effect of gender $(p=.07)$, but concern in the home of origin significantly predicted action, $F(1,602)=22.53, p<.01$, partial eta squared $=0.04$. Sidak adjusted post hoc tests reveal that the difference is between those with no college education and those with a bachelors degree or above $(p<.05)$ with those with less education exhibiting more action in concert with scientific consensus (see Table 1, Fig. 1). The group with some college education did not differ significantly from the other two.

These results repeat across most of the individual actions, as can be seen in Fig. 2, which shows the proportion of people who engage in the action "all of the time" or "most of the time."

To determine whether science education in particular has a different relationship to actions than education generally, we created a variable representing the relative depth of one's science education. That is, sums of the number of courses one took in high school and university across all science domains were binned based on standard deviations from the mean number of courses. ANCOVA showed a small main effect of science course taking, $F(3,601)=2.87, p<.05$, partial eta squared $=0.01$. There was no effect of gender $(p=.22)$, but concern in the home of origin significantly predicted action, $F(1,601)=22.17, p<.01$, partial eta squared $=0.04$. The differences

Table 1 Sidak adjusted post-hoc tests between education level groups

\begin{tabular}{llcl}
\hline Education level (I) & Education level $(\mathrm{J})$ & Mean difference (I-J) & $P$ \\
\hline No college, mean=3.31 & Some college & 0.18 & 0.28 \\
& Bachelors or more & 0.27 & $0.03^{*}$ \\
Some college, mean=3.13 & No college & -0.18 & 0.28 \\
& Bachelors or more & 0.09 & 0.30 \\
Bachelors or more, mean=3.04 & No college & -0.27 & $0.03^{*}$ \\
& Some college & -0.09 & 0.30 \\
\hline
\end{tabular}

*Value is statistically significant 


\section{Education Level on Action}

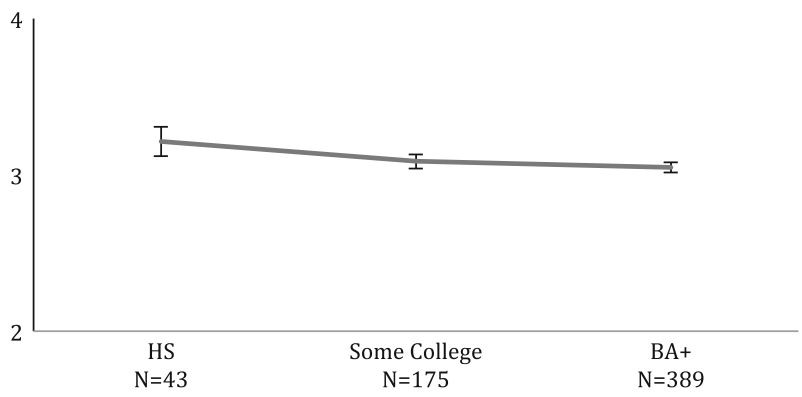

Fig. 1 Actions across general education level

between groups was not large enough to withstand a Sidak adjustment, but LSD post hoc tests reveal that those whose science course taking is more than one standard deviation above the mean are more likely to act in concert with scientific consensus than those who have taken a number of science courses that fall within one standard deviation from the mean. Those with the highest number of science courses are not, however, more likely than those with almost no exposure to science to behave in concert with scientific consensus (see Table 2, Fig. 3). Science education, then, when one reaches the highest levels, can have a positive effect on one's behavior, though the overall effect is small. In essence, high levels of science exposure can be helpful to a small degree, but lower levels of science exposure do not impact action.

To determine whether more targeted science education can make a larger difference for the average course taker, we created a variable representing the relative depth of one's biology and environmental science education. That is, sums of the number of courses one took in high school and university in biology or environmental science were binned based on standard deviations from the mean number of courses. ANCOVA (controlling for gender and concern in the home of origin) showed no effect of biology or environmental science course taking on one's likelihood to act in concert with scientific consensus, $F(3,601)=1.73, p=.16$.

One effect of a science education could be the influence of one's education on whether one perceives oneself as capable of consuming conflicting reports of science and coming to an informed conclusion. We refer to this as one's perceived knowledge attainment ability (PKAA). In a factor analysis, the five PKAA items factored together so closely that this overall perceived knowledge aggregate was used in each model $($ alpha $=0.96)$, indicating that

\section{Science Course Taking on Action}

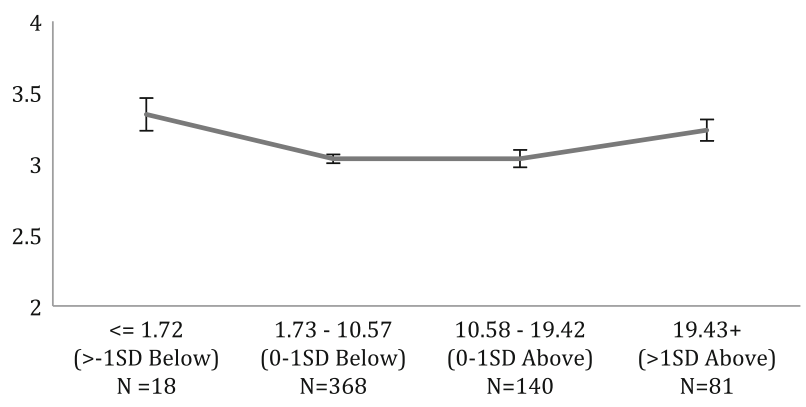

Fig. 2 Actions across science course-taking levels 
Table 2 LSD post hoc comparisons between science coursetaking groups

\begin{tabular}{llll}
\hline Science course taking (I) & Science course taking (J) & Mean difference (I-J) & $P$ \\
\hline Less than 1 SD below the mean, mean=3.40 & Within 1 SD below & 0.28 & 0.06 \\
& Within 1 SD above & 0.27 & 0.09 \\
& 19.43+ & 0.07 & 0.67 \\
Within 1 SD below the mean, mean=3.06 & Less than 1 SD below & -0.28 & 0.06 \\
& Within 1 SD above & -0.02 & 0.79 \\
& Greater than 1 SD above & -0.21 & 0.01 \\
Within 1 SD above the mean, mean=3.02 & Less than 1 SD below & -0.27 & 0.09 \\
& Within 1 SD below & 0.02 & 0.79 \\
Greater than 1 SD above the mean, mean=3.19 & Gess than 1 SD below & -0.07 & $0.03^{*}$ \\
& Within 1 SD below & 0.21 & 0.67 \\
& Within 1 SD above & 0.19 & $0.01^{*}$ \\
& & & $0.03^{*}$ \\
\hline
\end{tabular}

Mean overall science course taking is 10.56 , standard deviation, 8.85

*Value is statistically significant

one's perception of one's ability to attain knowledge is not highly content specific. Prior work indicates that PKAA is a significant and independent predictor of action in the home, and current analysis indicates that course taking is a significant predictor of PKAA, controlling for the impact of concern in the home of origin and education level $[F(3,605)=8.87, p<.01$, partial eta square $=0.04$ (see Fig. 4)]. The gain is seen with moderate amounts of course taking; intense course taking does not confer further benefits.

When both PKAA and course taking predict conservation action in the home (controlling for concern in the home of origin), both main effects remain [perceived knowledge attainment ability, $F=34.11, p<.01$, partial eta square $=0.05$; and course taking, $F=3.28, p<.05$, partial eta square $=$ $0.02]$ indicating that education is having an effect (though small) over and above PKAA.

\section{General Discussion}

Overall, we found a very weak relationship between science course taking and applied scientific literacy (and a negative relationship between general education and scientific

\section{Science Course Taking on Perceived Knowledge Attainment Ability}

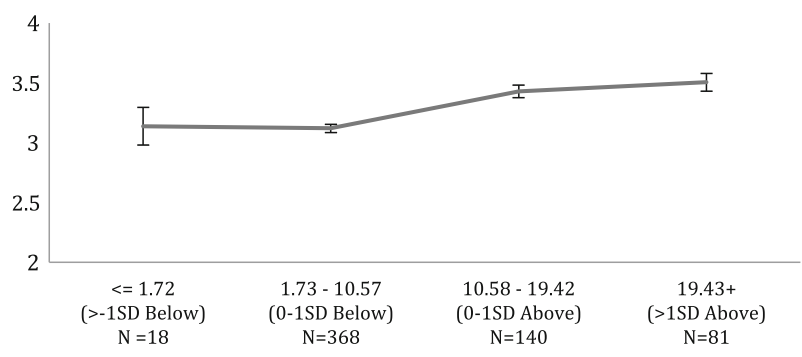

Fig. 3 The relationship between course-taking and perceived knowledge attainment ability 
literacy). Before falsely concluding that education broadly construed is not the key to this aspect of scientific literacy, it is important to examine the underlying theory of action.

There are several definitions of scientific literacy that precede the likelihood of scientific literacy predicting action; information from one's science education must be retained long enough to be used, and critical thinking must be in place to apply the retained knowledge to novel situations. Both retention of knowledge and the development of critical thinking can be called into question as outcomes of current science education (Conway, Cohen, and Stanhope 1991; Semb and Ellis 1994; American Association for the Advancement of Science 1989, 1993; National Research Council 1996, 2000; Anderson et al 1994). If typical science education experiences are ineffective in this regard, then the far transfer scenario (applying those foundations to real world situations) cannot be expected. Thus, it may still be the case that science education can produce scientifically informed action, but unfortunately, current science education of the kind most people receive does not.

In support of the idea that it is not the amount of science education per se but quality of science education that predicts scientific literacy is the fact that among the relationships we tested, science course taking had a positive impact only for those who had been exposed to a number of courses more than one standard deviation above the mean: that is, those who had taken more than 19 courses in science across high school and university showed greater scientific literate action than those who took a number of courses that fell within one standard deviation above or below the mean. To take this many classes, it is likely that these individuals are what Feinstein (2010) calls scientific insiders - they have begun to take on the mindset and habits of the mind of science. The rest are more likely to be what Feinstein calls marginal insiders, whose "understanding of science is fairly primitive, extending to experimentation but excluding probability and peer-review, and utterly neglecting the long and messy labors of authentic scientific work" (Feinstein 2010, p. 181). That is, it may be that only those reaching upper levels of science coursework develop the critical thinking skills necessary to apply knowledge to concrete situations. Alternatively, it maybe that more coursework produce knowledge that is less likely to be forgotten at longer delays (Bahrick 1984; Bahrick, Bahrick, Bahrick, and Bahrick 1993) or more coursework may produce more intense levels of interest or valuing of science, and it is the interest or valuing of science that drives later continued participation with science. Finally, there are those who argue that the notion of an adequately communicated scientific consensus that is preferable to a non-scientific perspective is to espouse a deficit model; it may be that even individuals with strong scientific content knowledge are not exposed to adequately communicated scientific perspectives that could inform their decisions (Miller, 2010).

\section{Science Course Taking on Perceived Knowledge Attainment Ability}

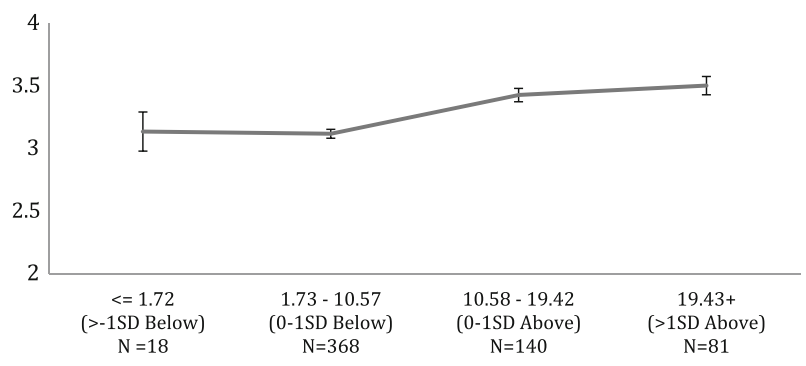

Fig. 4 The relationship between course-taking and perceived knowledge attainment 
Though it is less common to talk of scientific literacy as marked by the actions we take rather than simply by the knowledge we have, this applied perspective is often touted as a benefit of science knowledge. For example, the highly influential Benchmarks for Science Literacy note that science knowledge should "inform decisions on the uses of technology" and help one "deal sensibly with problems that often involve evidence, quantitative considerations, logical arguments, and uncertainty" (AAAS 1993, p. XI). The previous US National Science Education Standards state that "everyone needs to use scientific information to make choices that arise everyday" (NRC, 2005; p. 1). The new Framework for K-12 Science Education also notes "overarching goal of our framework for K-12 science education is to ensure that by the end of 12 th grade, all students ... are careful consumers of scientific and technological information related to their everyday lives" (National Research Council 2012, p. 1). Clearly, science education policy makers intended for science knowledge to transfer to everyday decisions.

To meet these expectations, science education will need to be restructured. Certainly, it must move away from rhetoric of conclusions (Schwab 1962) and towards a more constructed and active learning endeavor (National Research Council 2007; AAAS 1993). Science education would certainly benefit from taking on the practices and procedures of professional science such as argumentation and inquiry, as many have argued (Bricker and Bell 2008; Ford 2015; Kuhn 2005) and are now highlighted in the Next Generation Science Standards. To meet the specific particular intentions of applied scientific literacy such as community stewardship, however, it may be that science education needs to shift from the practices and knowledge of professional science (the focus of many current reform efforts) towards the principles and consequences of community stewardship in particular (Feinstein 2010).

\section{Limitations and Future Work}

This report advances the interpretation of a lack of a relationship between variables: essentially that the amount of science education does not predict applied scientific literacy. As such, it is critically important that we address any measurement concerns. One concern might be that our measure of applied scientific literacy is based on self-report, which can be inaccurate. However, our interpretations rely on comparative levels of actions, and any noise that exists in our measure likely exists at all levels of education, and the social pressure to misrepresent their literate actions is likely to be highest among the most educated. Further, the pattern of results is essentially the same across all actions examined, some of which are less frequent/more salient (e.g., driving behaviors) and thus less likely to be misremembered. Yet, it would be useful to replicate these results with observational data and perhaps with other issues of scientific concern that may be less subject to self-report biases.

Similarly, our measure of science education is based on one's self-reporting of classes that were often taken many years before. While there is validity in this concern, we attempted to temper the effect of faulty memory by using standard deviation distance from the average as our binning variable. This allows for comparing people with very different levels of exposure without relying on precise memories about every indicated course. Additionally, these reports are also analyzed comparatively, providing the same protection as mentioned in the discussion of the dependent variable. If there were systematic memory biases, the most likely bias would be for people engaged in literate action to be more likely to remember prior coursework. Finally, our measure of amount of science education is related to one's perceived knowledge attainment ability in a manner that one would expect, providing some concurrent validity.

Replication across a randomly chosen sample would add confidence since participation was voluntary (although with some financial incentive for participation) and could be biased towards individuals who value environmental conservation actions. Additionally, replication from more 
varied samples and samples with a higher response rate would ensure that these results are not restricted to civil servants from the American Midwest who are agreeable to taking surveys.

While we must be careful in our interpretations, these results do provide some evidence that amount of science education is not a sufficient determinant of whether one acts in concert with scientific consensus. While we argue that the onus may well be on the type of science education most people receive, we also acknowledge that other factors could simply be more impactful. For example, in previous work (Crowell and Schunn 2014) practical concerns, a sense of social responsibility and convenience were found to be independent predictors of applied scientific literacy. At the very least, the argument that science education writ large will benefit everyday decision making should not be taken as self-evident truth; future models of the relationship between scientific literacy and education must be more complex and sensitive to the impact of personal perceptions, practical concerns, and the quality of the educational experience.

Acknowledgments This study was funded by a grant from the Gordon and Betty Moore Foundation to the Christian Schunn.

\section{Appendix A: Example Question: Recycling}

Recycling

1) How often do you recycle AT HOME?*

( ) All the time

( ) Most of the time

( ) Sometimes

( ) Rarely

( ) Never

2) Please indicate how much you agree with each statement about recycling AT HOME. (Please place a check mark in one box for each row)*

\begin{tabular}{l}
\hline Strong agree \\
Recycling at home makes a big difference to \\
environmental sustainability \\
Recycling at home saves money \\
Recycling at home is convenient \\
Recycling at home sets a good example for others \\
Recycling at home is a responsible thing to do
\end{tabular}

5) Imagine you are at a party where two people are arguing about the importance of recycling. One person says that recycling has NO long-term impact on environmental sustainability. You decide to do some research to figure out who is right.

How sure are you that you have the science knowledge to understand what you read?*
( ) Very Sure
( ) Sure
( ) Less sure
( ) Not sure at all 


\section{References}

American Association for the Advancement of Science. (1989). Project 2061: science for all Americans. Washington: Author.

American Association for the Advancement of Science. (1993). Benchmarks for science literacy. Oxford: Oxford University Press.

Anderson, R. D., Anderson, B. L., Varank-Martin, M. A., Romagnano, L., Bielenberg, J., Flory, M., Mieras, A. B., \& Whitworth, J. (1994). Issues of curriculum reform in science, mathematics, and higher order thinking across the disciplines (Curriculum Reform Project Series 0-16-043073-9). Washington: U.S. Department of Education.

Bahrick, H. P. (1984). Semantic memory content in permastore: fifty years of memory for Spanish learned in school. Journal of Experimental Psychology: General, 113(1), 1.

Bahrick, H. P., Bahrick, L. E., Bahrick, A. S., \& Bahrick, P. E. (1993). Maintenance of foreign language vocabulary and the spacing effect. Psychological Science, 4(5), 316-321.

Bandura, A. (1986). Social foundations of thought and action: a social cognitive theory. Englewood Cliffs: Prentice-Hall.

Bandura, A. (2001). Guide for constructing self-efficacy scale (monograph). Stanford: Stanford University.

Bricker, L. A., \& Bell, P. (2008). Conceptualizations of argumentation from science studies and the learning sciences and their implications for the practices of science education. Science Education, 92(3), 473-498.

Bybee, R., \& Fuchs, B. (2006). Preparing the 21st century workforce: a new reform in science and technology education. Journal of Research in Science Teaching, 43(4), 349-352.

Carroll, B., \& Loumidis, J. (2001). Children's perceived competence and enjoyment in physical education and physical activity outside of school. European Physical Education Review, 7(1), $24-43$.

Conway, M. A., Cohen, G., \& Stanhope, N. (1991). On the very long-term retention of knowledge acquired through formal education: twelve years of cognitive psychology. Journal of Experimental Psychology: General, 120(4), 395.

Crowell A., \& Schunn, C. (2014). Scientifically literate action: Key barriers and facilitators across context and content. Public Understanding of Science, 23(6):718-33.

DeBoer, G. E. (2000). Scientific literacy: another look at its historical and contemporary meanings and its relationship with science education reform. Journal of Research in Science Teaching, 37(6), 582-601.

Durack, P. J., Wijffels, S., \& Matear, R. J. (2012). Ocean salinities reveal strong global water cycle intensification during 1950 to 2000. Science, 336, 455-458.

Feinstein, N. (2010). Salvaging science literacy. Science Education, 95(1), 168-185.

Feinstein, N. (2012). Making sense of autism: progressive engagement with science among parents of young, recently diagnosed autistic children. Public Understanding of Science. doi:10.1177/0963662512455296. Published Online September, 5, 2012.

Ford, M.J. (2015). A dialogic account of sense-making in scientific argumentation and reasoning. Cognition and Instruction.

Hofer, B. K., \& Pintrich, P. R. (1997). The development of epistemological theories: beliefs about knowledge and knowing and their relation to learning. Review of Educational Research, 67, 88-140.

Hurd, P. (2000). Science education for the 21st century. School Science and Mathematics, 100(6), 282.

Intergovernmental Panel on Climate Change. (2007a). Summary for policymakers. In S. Solomon, D. Qin, M. Manning, Z. Chen, M. Marquis, K. B. Averyt, M. Tignor, \& H. L. Miller (Eds.), Climate change 2007: The physical science basis. Contribution of working group I to the fourth assessment report of the intergovernmental panel on climate change (pp. 1-18). Cambridge: Cambridge University Press.

Intergovernmental Panel on Climate Change. (2007b). Summary for policymakers. In M. L. Parry, O. F. Canziani, J. P. Palutikof, P. J. van der Linden, \& C. E. Hanson (Eds.), Climate change 2007: Impacts, adaptation and vulnerability. Contribution of working group II to the fourth assessment report of the intergovernmental panel on climate change (pp. 7-22). Cambridge: Cambridge University Press.

Jenkins, E. (1999). School science, citizenship and the public understanding of science. International Journal of Science Education, 21, 703-710.

Kuhn, D. (2005). Education for thinking. Harvard: Harvard University Press.

Miller, J. (1983). Scientific literacy: a conceptual and empirical review. Daedalus, 112, 29-48.

Miller, J. (2004). Public understanding of, and attitudes toward, scientific research: what we know and what we need to know. Public Understanding of Science, 13, 273-294.

Miller, J. D. (2010). The conceptualization and measurement of civic scientific literacy for the 21 st century. In Meinwald, J. and Hildebrand, J. G. (Eds.), Science and the Educated American: A core component of liberal education (pp. 241-255). Cambridge, MA: American Academy of Arts and Sciences.

National Center on Education, \& the Economy (US). New Commission on the Skills of the American Workforce, \& New Commission on the Skills of the American Workforce. (2007). Tough choices or tough times: the report of the new commission on the skills of the American workforce. San Francisco: Jossey-Bass. 
National Research Council. (1996). National science education standards: observe, interact, change, learn. Washington: National Academy Press.

National Research Council. (2000). Inquiry and the national science education standards. Washington: National Academy Press.

National Research Council. (2005). National Science Education Standards. Washington, DC: National Academy Press.

National Research Council. (2007). Taking science to school: learning and teaching science in grades K-8. Washington: National Academy Press.

National Research Council. (2012). A framework for K-12 science education: practices, crosscutting concepts, and core ideas. Washington: The National Academies Press.

Norris, S. P., \& Phillips, L. M. (2003). How literacy in its fundamental sense is central to scientific literacy. Science Education, 37, 224-240.

OECD. (2006). Assessing scientific, reading and mathematical literacy: a framework for PISA 2006. Paris: OECD.

Peerson, A., \& Saunders, M. (2009). Health literacy revisited: what do we mean and why does it matter? Health Promotion International, 24(3), 285-296.

Phillips, L. M., \& Norris, S. P. (1999). Interpreting popular reports of science: what happens when the reader's world meets the world on paper? International Journal of Science Education, 21, 317-327.

Rabin, R. C. (2012). Study finds sharp climb of diabetes in youth. New York Times. Retrieved October 8, 2012 from http://health.nytimes.com.

Roberts, D. A. (2007). Scientific literacy/science literacy. In S. K. Abell \& N. G. Lederman (Eds.), Handbook of research in science education (pp. 729-779). Mahwah: Erlbaum.

Roschelle, J., Bakia, M., Toyama, Y., \& Patton, C. (2011). Eight issues for learning scientists about education and the economy. The Journal of the Learning Sciences, 20(1), 3-49.

Schwab, J. (1962). The teaching of science as enquiry, the teaching of science (pp. 3-103). Cambridge: Harvard University Press.

Semb, G. B., \& Ellis, J. A. (1994). Knowledge taught in school: what is remembered? Review of Educational Research, 64(2), 253-286.

Sismondo, S. (2004). An introduction to science and technology studies. Malden: Blackwell Publishing.

Sutman, F. X. (1996). Scientific literacy: a functional definition. Journal of Research in Science Teaching, 33, $459-460$.

Thomas, D., \& Brown, J. S. (2011). A new culture of learning: cultivating the imagination for a world of constant change. Lexington: CreateSpace. 